Departamento de Química Orgânica e Biológica Diretor: Prof. Dr. Fonseca Ribeiro

\title{
MÉTODO DE DOSAGEM DO FLUOR NA ÁGUA (*)
} POR

\section{T. L. Araujo \\ Assistente}

O "Standard Methods" para exames de água indica para determinações do fluor o método de SANCHIS, que requer a preparação duma série de padrões contendo quantidades crescentes de fluoreto de sódio. A cada um destes é juntada uma mesma quantidade de reativo, obtendo-se deste modo, uma escala colorida de intensidade decrescente com a qual compara-se à amostra em exame após ela ter sido tambem tratada pela mesma quantidade de reativo. Este último é constituido por zircónio-alizarina, que se prepara misturando volumes iguais das soluções aquosas de oxicloreto de zircónio $(0,5 \mathrm{gr}$. elevada a $100 \mathrm{cc}$.) e monosulfato de sódio alizarina ( $0,1 \mathrm{gr}$. elevado a $100 \mathrm{cc}$. $)$. O volume total é diluido com o dobro de água distilada. O reativo assim obtido deve ser conservado em geladeira e usado no espaço de poucos dias, pois, em caso contrário deixa de ser sensivel para águas com teor baixo em fluor. Na análise quantitativa do fluor pelo método de SANCHIS é mister levar-se em conta o conteudo em cloretos e sulfatos das águas, pelo menos o teor em sulfatos. Tais sais devem estar presentes nos padrões nas mesmas quantidades em que ocorrem nas águas a serem analisadas. Contudo no caso dos sólidos totais não excederem $500 \mathrm{p}$. p. m. é bastante que os padrões contenham apenas sulfatos, obtendo-se ainda assim resultados razoáveis.

Cada 50 cc. da água a ser examinada recebe 5 cc. de ácido clorídrico $5 \mathrm{~N}$ e $1 \mathrm{cc}$. do reativo zircónio-alizarina. Porções iguais dos padrões são tratadas pelos mesmos reativos e a comparação é feita em tubos de Nessler após 18 horas de permanência à temperatura ambiente. Realizando ensaios por este método encontramos sérias dificuldades para fazer as leituras, pois, dum padrão ao outro a diferença de coloração era geralmente insensivel mesmo quando as quantidades de fluoreto de sódio dum tubo ao outro diferiam em $0,2 \mathrm{mg}$.

Além disso é sabido terem nossas águas de abastecimento, em geral, pequeníssimas porções de sais, tais como sulfatos e cloretos sendo praticamente comparáveis à água distilada, de modo que as águas pa- 
drões são preparadas tambem com estas características o que contribue para a conservação quase integral da cor do reativo e dificuldade de leitura. Para contornar tais inconvenientes por sugestões do Prof. FONSECA RIBEIRo introduzimos algumas modificações no método de SANCHIS, conseguindo resultados satisfatórios. Tais modificações dizem respeito ao preparo dos reativos e ao modo de proceder. Possivelmente o maior interesse delas esteja no fato de ser evitada a preparação de águas padrões o que evidentemente é uma simplificação.

REATIVOS

$1 .^{\circ}$ - O reativo zircónio-alizarina passou a ser preparado do modo seguinte:

1 cc. de solução de oxicloreto de zircónio $\left(0,5 \mathrm{gr}\right.$. de $\mathrm{ZnOCl} .8 \mathrm{H}^{2} \mathrm{O}$ elevada à 100 cc. com água distilada) mais 1 cc. da solução de monosulfato de sódio alizarina $(0,1 \mathrm{gr}$. elevada à $100 \mathrm{cc}$. com água distilada) e o todo elevado à $50 \mathrm{cc}$. com água distilada.

$2 .^{\circ}$ - O ácido clorídrico passou a ser usado com o título de $0,5 \mathrm{~N}$.

Procurou-se saber quanto de fluor sob forma de fluoreto de sódio é necessário para descorar inteiramente uma determinada quantidade de zircónio-alizarina e chegou-se a conclusão de que 0,1 cc. do reativo correspondiam a $0,00125 \mathrm{mg}$. de fluor. Este resultado foi obtido por tentativas, sendo as últimas, precisamente aquelas que deram resultados constantes, quando repetidas em condições idênticas, realizadas como segue: numa série de tubos de Nessler foi colocado, em cada tubo $50 \mathrm{cc}$. duma solução de $\mathrm{FNa}$ com $0,025 \mathrm{mg}$. de $\mathrm{F}$ mais $5 \mathrm{cc}$. de ácido clorídrico e mais respectivamente 0,$0 ; 0,2 ; 0,3 ; 0,4 ; 0,5 ; 0,6$ do reativo zircónio-alizarina. Após duas horas de repouso à temperatura do laboratório os três primeiros tubos mostraram-se completamente descorados enquanto do quarto em diante persistia uma coloração rósea, progressivamente acentuada. Esta coloração conservou-se estavel por mais de 12 horas. O "blank" para este volume é igual a 0,2 cc.

E' possivel, pois, determinar o teor em fluor duma água sem preparar padrões para comparação. Sabendo-se que $0,1 \mathrm{cc}$. do reativo preparado da maneira indicada acima corresponde à $0,00125 \mathrm{mg}$. de fluor será bastante colocar em cada tubo de Nessler duma série volumes iguais da amostra em exame (50 cc. p.e.) e 5 cc. de ácido clorídrico $0,5 \mathrm{~N}$. Juntar quantidades crescentes do reativo a partir de 0,0 e realizar a leitura após duas horas de repouso. Será considerado positivo o tubo com a menor quantidade de reativo que mostrar ligeira coloração rósea. Desta subtrae-se o "blank" e por meio duma simples proporção tem-se o teor em fluor da água, em partes por milhão. 
Esta modificação do método de SANCHIS dá resultados aceitaveis, o que nos foi possivel comprovar não só por meio de soluções padrões de FNa como tambem repetindo uma observação de BoRUFF e outros autores, relativa ao acarretamento do fluor pelo sulfato de alumínio, comumente empregado no tratamento de águas. BoRUFF notou diminuição de fluor de 3 para 1 em águas depois de tratadas com $0,12 \mathrm{gr}$. de sulfato por galão $(4.545 \mathrm{cc}$.) e de 5 para 1 quando tratadas por mais ou menos 0,6 gr. por galão. Repetindo estas observações pudemos notar que uma solução de fluoreto de sódio com 1 p.p.m. passava a dosar 0,5 p.p.m. ou 0,3 p.p.m. de acordo com as quantidades de sulfato de alumínio e de cal empregadas. Do mesmo modo houve redução de $0,6 \mathrm{e}$ 0,5 p.p.m. para 0,5 e 0,4 p.p.m. respectivamente após o mesmo tratamento. 